IZA DP No. 4549

Redistributive Politics and Market Efficiency: An Experimental Study

Jens Großer

Ernesto Reuben

November 2009 


\title{
Redistributive Politics and Market Efficiency: An Experimental Study
}

\author{
Jens Großer \\ Florida State University \\ Ernesto Reuben \\ Columbia University \\ and IZA
}

Discussion Paper No. 4549

November 2009

IZA

P.O. Box 7240

53072 Bonn

Germany

Phone: +49-228-3894-0

Fax: +49-228-3894-180

E-mail: iza@iza.org

Any opinions expressed here are those of the author(s) and not those of IZA. Research published in this series may include views on policy, but the institute itself takes no institutional policy positions.

The Institute for the Study of Labor (IZA) in Bonn is a local and virtual international research center and a place of communication between science, politics and business. IZA is an independent nonprofit organization supported by Deutsche Post Foundation. The center is associated with the University of Bonn and offers a stimulating research environment through its international network, workshops and conferences, data service, project support, research visits and doctoral program. IZA engages in (i) original and internationally competitive research in all fields of labor economics, (ii) development of policy concepts, and (iii) dissemination of research results and concepts to the interested public.

IZA Discussion Papers often represent preliminary work and are circulated to encourage discussion. Citation of such a paper should account for its provisional character. A revised version may be available directly from the author. 
IZA Discussion Paper No. 4549

November 2009

\section{ABSTRACT}

\section{Redistributive Politics and Market Efficiency: An Experimental Study*}

We study the interaction between competitive markets that produce large but unequally distributed welfare gains and elections through which the poor majority can redistribute income away from the rich minority. In our simple laboratory democracy, subjects first earn their income by trading in a double auction market and thereafter vote on redistributive policies in two-candidate elections. In addition, in one of the treatments subjects can attempt to influence the candidates' policy choices by transferring money to them. We observe very high levels of redistribution - even when transfers to candidates are possible - with little effect on market efficiency. Overall, the experimental results are explained by our equilibrium predictions.

JEL Classification: H23, D41, D72, D73

Keywords: redistribution, double auction, elections, lobbying

Corresponding author:

Ernesto Reuben

Columbia Business School

3022 Broadway

Uris Hall

New York, NY 10027

USA

E-mail: ereuben@columbia.edu

\footnotetext{
* Financial support from the GEW Foundation Cologne and the German Science Foundation (DFG) is gratefully acknowledged. We would also like to thank the Economics Laboratory of the University of Cologne for their help and hospitality. Moreover, we received many useful suggestions from Jon Rogers and participants of the 2005 CREED-CeDEx Mini-workshop, the 2007 ESA Meeting in Tucson, the 2008 International ESA Meeting in Pasadena, the 2008 WEA Meeting in Waikiki, the 2009 North American Econometric Society Meeting, and seminars at Florida State University and Université Laval.
} 


\section{Introduction}

Modern democracies rely on two vital institutions: markets and elections. Citizens regularly participate in a variety of markets and, in this way, generate welfare. However, this welfare is typically unequally distributed. For example, in the Netherlands the top quintile gets $40 \%$ and the two top quintiles $62 \%$ of the total pre-tax income. For the United States these numbers are 45\% and 69\% (World Bank Annual Report 2007). ${ }^{1}$ By contrast, by participating in elections, citizens have the opportunity to moderate welfare inequalities. Namely, if those with incomes in the bottom three quintiles support a strong redistributive policy, they could substantially reduce-even eliminate-the welfare gap between the rich and themselves. However, this is in stark contrast to the observed persistence throughout the world of a majority of citizens earning incomes below the national average. In other words, neither governments nor the poor seem to endorse largely egalitarian incomes. In this paper, we study whether income inequalities can persist in a laboratory experiment where subjects earn their incomes in markets and thereafter vote on redistributive taxes in two-candidate elections. The laboratory allows us to directly measure the welfare and redistribution effects of the interaction of these two institutions in a controlled environment.

So far, experimental markets and elections have been studied in isolation. Many laboratory markets - in particular the double auction market of Smith (1962)-reliably clear at equilibrium quantities and prices, and in this way generate full efficiency, that is, they produce the maximum possible welfare (for surveys see, Davis and Holt 1993; Kagel and Roth 1995). Similarly, laboratory elections with compulsory simple majority voting reliably result in outcomes preferred by the majority (for a survey see, McKelvey and Ordeshook 1990). While the large experimental literature on both institutions has substantially contributed to our understanding of how markets and elections function, it sheds relatively little light on the performance of these institutions when they coexist. How is market performance affected by redistributive taxes? In anticipation of possible effects on market

\footnotetext{
${ }^{1}$ See also Milanovic, Lindert, and Williamson (2007) for evidence that hunter gatherer societies, which are more autarkic, display less income inequality than both modern and ancient cities, which have market economies.
} 
outcomes, to what extent do poor majorities support redistribution? Do rich minorities utilize their higher incomes to influence election outcomes and the level of redistribution?

In our experiment, citizens first earn their-unequally distributed-income in a double auction market (Smith 1962), thereafter, two candidates select redistributive tax policies and compete in simple majority elections in which all citizens get to vote. To mimic the income inequalities observed in democracies around the world, we chose the market parameters such that, in equilibrium, there is a rich minority and a poor majority. Hence, candidates have an incentive to woo the poor with high redistribution. In an additional setup, citizens also have the opportunity to lobby, that is, to transfer money to the candidates. If candidates respond to these transfers-they have no obligation to do so-the high concentration of pre-tax income gives the rich minority an advantage over the poor in influencing redistributive policies. In other words, the principle of "one person, one vote", which gives each citizen the same political influence, may be counteracted by the principle of "one dollar, one vote", which translates into more influence by the rich.

We think our experimental setup is of particular interest because it captures three prevalent facts. First, most countries have a poor majority with pre-tax incomes that lie well below the national average. Second, governments are capable of redistributing resources from the rich to the poor. Third, modern democracies have numerous special interest groups that use-legal and illegal-means to transfer resources to candidates with the purpose of influencing redistributive policies. Therefore, our basic experimental setup can shed light on two puzzling phenomena in modern democracies: namely, the high concentration of aftertax income in a minority of citizens, ${ }^{2}$ and the common practice of lobbying by compensating political candidates in spite of the impossibility of writing enforceable contracts (e.g., due to legal prohibition).

It is well known that too much redistribution may reduce, or even destroy, the markets' ability to produce welfare gains, in which case, high levels of redistributive taxes may not be in the interest of the poor. There are numerous means through which

\footnotetext{
2 According to the 2007 World Bank Annual Report, in all democracies a majority of citizens have below-average after-tax income.
} 
redistribution can negatively affect market performance. ${ }^{3}$ In this paper, we concentrate on welfare losses that result from individuals abstaining from market activity or trading carelessly because of lower marginal incentives. We use a double auction market (Smith 1962) because it has been shown to reliably produce efficient outcomes in experiments without redistribution. Hence, we test whether these markets are robust in the more realistic environment where traders anticipate that their market incomes will be redistributed. In the double auction market, even with full redistribution (i.e., everyone gets the same after-tax earnings) there is a small incentive to trade. As a consequence, standard equilibrium analysis - that is, supply and demand analysis-predicts that the double auction market is efficient in spite of redistributive taxation. However, it is reasonable to conjecture that redistributive taxation may affect market activity and outcomes (e.g., price volatility and efficiency) in ways not foreseen by market equilibrium. For example, many experiments have demonstrated the impact of reduced marginal incentives (e.g., Goeree and Holt 2001; Isaac and Walker 1988; McKelvey and Palfrey 1995; 1998), which in the double auction market translates to careless trading and an increased probability of inefficient transactions. Moreover, there is a large literature on intentions and bargaining that suggests that depriving people of their 'fair' share of a surplus, such as with taxes that are 'too high', can lead to emotional retaliation through the destruction of income (e.g., Bosman and van Winden 2002; Camerer 2003), which in our setting can be achieved by abstaining from market activity.

No doubt, political decision making unavoidably evokes conflict between those involved. Here is where special interest groups, or lobbyists, enter the political arena. The resources used by lobbyists are far from being marginal. For example, in the United States a total of 14,838 lobbyists spent $\$ 3.30$ billion on lobbying in $2008 .{ }^{4}$ In this paper, we are interested in whether and, if so, how monetary transfers to the candidates prior to policy making can influence income redistribution. As in most democracies, transfers to candidates

\footnotetext{
${ }^{3}$ For example, high redistribution may decrease the poor's income if it reduces economic growth (e.g., Browning 2002) or stimulates migration of the more productive members of society to other countries.

${ }^{4}$ Data from http://www.opensecrets.org/lobby/index.php (from August 20, 2009).
} 
do not bind the candidates' actions and therefore the effectiveness of lobbying depends on whether candidates decide to reciprocate lobbying efforts. Moreover, because the opportunity to lobby is given to both rich and poor, counteractive lobbying may arise (Austen-Smith and Wright 1992, 1994). Thus, even if candidates choose full redistribution, the poor majority may lobby in order to weaken or outweigh the lobbying attempts towards lower taxation of the rich. ${ }^{5}$ Lastly, in our setup any kind of explicit coordination, such as communication, is prohibited, which creates a challenging task for all involved in the lobbying process. For example, it is not immediately obvious what a successful lobbying strategy is-in the field, lobbyist make similar campaign contributions to both preferred and non-preferred candidates-and after receiving money candidates still need to coordinate on a redistributive policy in order to keep money flowing in the future. Note that all pre-tax market incomes in the society are public information and, in this respect, there is no informational role for lobbyists to play (as it does in Ainsworth 1993; Grossman and Helpman 2001; Potters and van Winden 1992; 2000).

By keeping our laboratory democracy simple, we obviously omit a variety of plausible explanations of why income distributions are not more egalitarian. These include, but are not limited to: expected social mobility (e.g., Alesina and La Ferrara 2005; Alesina and Rodrik 1994; Benhabib and Rustichini 1996), economic inefficiencies caused by redistribution such as leaky buckets (Browning 2002), the existence of outside options (e.g., tax migration), corruption of courts and political processes (e.g., Glaeser, Scheinkman, and Shleifer 2002), concerns for the survival of democracy (Benhabib and Przeworski 2006), and different benchmarks of equality such as 'equality of opportunity' and 'equality of outcomes' (Bénabou and Tirole 2006). ${ }^{6}$ Hence, our experiment can be seen as a first step in studying in

\footnotetext{
5 As in many rent seeking models, we model lobbying transfers as sunk costs (e.g., Tullock 1980) which remain with the candidates irrespective of their redistributive policies. See Großer, Reuben, and Tymula (2009a,b) for cases in which counteractive lobbying by the poor is not possible and Großer, Reuben, and Tymula (2009b) for a case where candidates are rewarded after they have chosen their redistributive policy.

${ }^{6}$ For more comprehensive discussions see Browning (2002), Persson and Tabellini (2000), and Rosen and Gayer (2007). Bénabou (2000) relates differences in redistribution between countries to imperfect credit and insurance
} 
isolation some of the means though which markets and elections interact and the welfare consequences of this interaction.

To the best of our knowledge, this is the first laboratory experiment that studies how markets and elections function when they coexist. Related to our study are the experiments of Durante and Putterman (2009) and Esarey, Salmon, and Barrilleaux (2009). Durante and Putterman (2009) study the importance of fairness preferences and risk aversion in determining support for redistribution, distinguishing between earned and unearned income, choices of involved subjects and outside observers, and certainty and uncertainty about pre-tax earnings. They find that self-interest and risk-aversion can explain most of the support for redistributive policies and that redistribution is greater when income is 'earned' rather than 'unearned'. Esarey, Salmon, and Barrilleaux examine the degree to which redistributive taxation can be explained by fairness-based voting in elections. In their experiment, subjects earn pre-tax incomes in a real effort task and "vote" by proposing tax rates from which the median proposal is chosen. They find that voting is primarily motivated by self-interest and that productivity is not affected by taxation. By contrast, Tyran and Sausgruber (2006) study voting where a poor minority cannot achieve redistribution on its own. However, they show that redistribution occurs due to enough rich and middle income subjects being motivated by fairness concerns. Our study is different from these two experiments in various respects. For example, we investigate the effect of redistribution on markets, allow for endogenous tax policies through candidate competition, and we also examine the effect of lobbying on elections.

\section{Experimental games}

In this section, we describe our experimental games. In each game there is a society of $i=1, \ldots, 10$ citizens and in two games there are also two candidates, $j=A, B$.

\footnotetext{
markets. There is also a literature that studies the positive effect of inequality on the level of redistribution, caused by a poorer median voter in more unequal societies (e.g., Meltzer and Richard 1981; Romer 1975). Finally, Campante (2007) studies redistribution when political participation (i.e, voting and campaign contributions) is endogenous.
} 


\subsection{Markets with exogenous redistributive taxation}

This game is a standard double auction market (Smith 1962) with the added twist that market incomes may be subject to exogenously-determined redistributive taxation. Each citizen is assigned to be one of the five sellers or five buyers in the market. Each seller and buyer can trade up to two units of a homogenous good. Seller $i$ earns $\pi_{i 1}^{S}=p_{i 1}-c_{i 1}$ if she sells her first unit plus $\pi_{i 2}^{S}=p_{i 2}-c_{i 2}$ if she sells her second unit, where $c_{i k}$ denotes her cost of producing-or minimum willingness to accept-the $k^{\text {th }}$ unit and $p_{i k}$ the price she receives for it. Similarly, buyer $i$ earns $\pi_{i k}^{b}=v_{i k}-p_{i k}$ if she purchases her $k^{\text {th }}$ unit, where $v_{i k}$ denotes her value-or maximum willingness to pay-for the $k^{\text {th }}$ unit and $p_{i k}$ the price she pays for it. Units that are not traded yield zero-income. Both $c_{i k}$ and $v_{i k}$ are exogenous and vary across citizens and units (the specific parameters used in our experiment and the resulting supply and demand curves are shown in Figure 1). In summary, each seller's pre-tax market income is given by $\pi_{i}^{s} \equiv d_{i 1} \pi_{i 1}^{s}+d_{i 2} \pi_{i 2}^{s}$ and each buyer's pre-tax market income by $\pi_{i}^{b} \equiv d_{i 1} \pi_{i 1}^{b}+$ $d_{i 2} \pi_{i 2}^{b}$, where $d_{i k}=1$ if she trades her $k^{\text {th }}$ unit and $d_{i k}=0$ otherwise. In the experiment, earnings were expressed in points, which were exchanged for cash at a rate of €1 for 17 points at the end of the session.

The following trading and information rules apply: ${ }^{7}$ (i) the market opens for two minutes; (ii) for their $k^{\text {th }}$ (untraded) unit, sellers can post an integer price $p_{i k} \in\left\{c_{i k}, \ldots, s_{S}-\right.$ $1\}$, where $s_{s} \leq 100$ denotes the standing seller price (i.e., the current lowest price posted by a seller or 100 if there is no posting so far), and buyers can post an integer price $p_{i k} \in$ $\left\{s_{b}+1, \ldots, v_{i k}\right\}$, where $s_{b} \geq 0$ denotes the standing buyer price (i.e., the current highest price posted by a buyer or 0 if there is no posting so far); (iii) sellers can accept a standing buyer price (i.e., $p_{i k}=s_{b}$ ), as long as $p_{i k} \geq c_{i k}$ and buyers can accept a standing seller price (i.e., $p_{i k}=s_{s}$ ), as long as $p_{i k} \leq v_{i k}$, which means that pre-tax incomes are always nonnegative; (iv) each seller and buyer must trade her units one at a time, starting with the first unit; (v) buyers cannot resell units they have bought; (vi) if a transaction occurs, standing

\footnotetext{
7 These rules and our parameters are similar to those used in typical experiments of double action markets (see Davis and Holt 1993; Kagel and Roth 1998).
} 


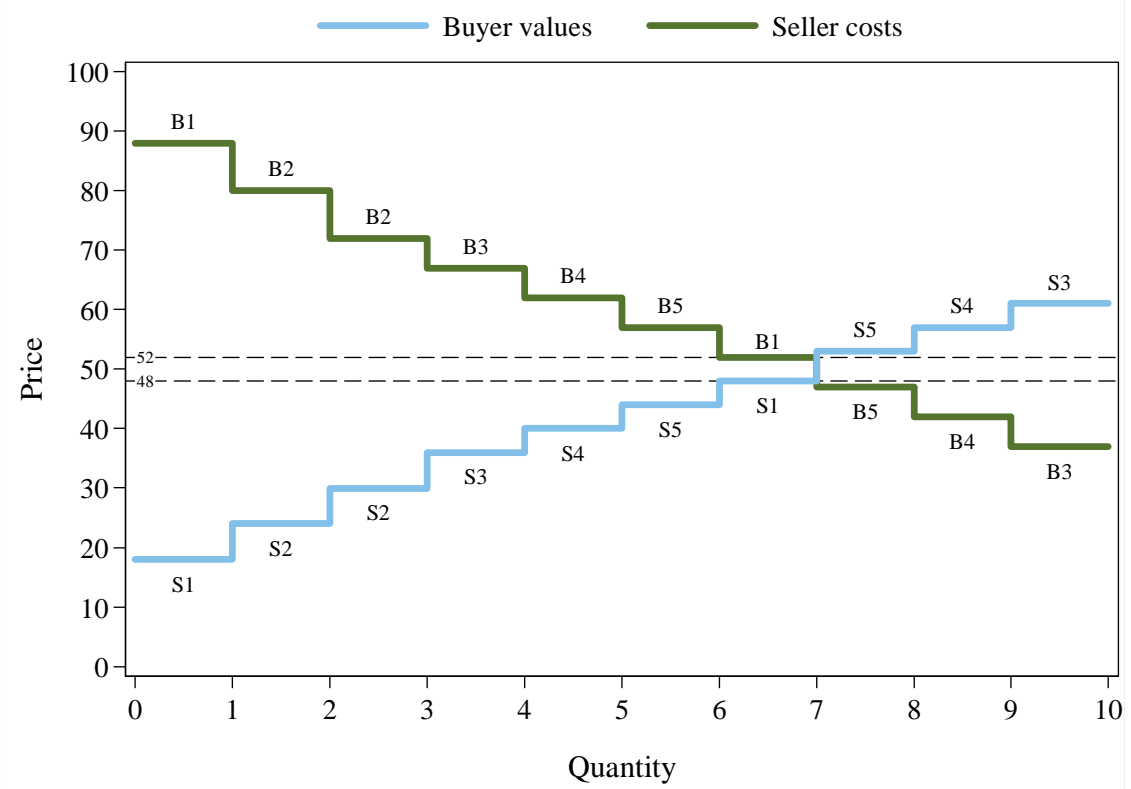

Figure 1 - Supply and demand in the double auction market

Note: The figure shows the costs assigned to the five sellers (labeled S1,..., S5) and the values assigned to the five buyers (labeled B1,.., B5). On the supply curve, each step represents the cost of one of the $k=1,2$ units of the good, $c_{i k}$, where $c_{i 1}<c_{i 2}$ for each seller $i$. Similarly, on the demand curve, each step represents the value of one of the $k=1,2$ units of the good, $v_{i k}$, where $v_{i 1}>v_{i 2}$ for each buyer $i$. Supply and demand curves intersect at $q=7$ quantities and prices $p \in\{48, \ldots, 52\}$ (only integer prices were allowed in the experiment).

prices are removed and the posting and accepting of prices starts all over again until the market closes; (vii) communication is not allowed (traders can only observe all posted and accepted prices); and finally, (viii) it is public information that rules (i) to (vii) hold, that there are five sellers and five buyers, and that each trader is informed about her own costs or values but not the costs and values of others. ${ }^{8}$

In contrast to standard double auction markets, we introduce an exogenous tax rate, $t \in[0,1]$, that determines the degree of income redistribution among citizens and is public information when the market opens. Specifically, each citizen $i$ 's final payoff (i.e., after-tax market income) is given by $\pi_{i, t a x} \equiv \pi_{i}+T_{i}$, with $T_{i} \equiv t\left(\bar{\pi}-\pi_{i}\right)$ being her positive or negative transfer payment and $\bar{\pi} \equiv \frac{1}{10} \sum_{h=1}^{10} \pi_{h}$ the average pre-tax market income of all

\footnotetext{
8 In our experiment, subjects repeatedly participated in the same double auction market and their roles, costs, and values never changed.
} 
citizens. Thus, each citizen $i$ with pre-tax income strictly smaller than average may receive a transfer payment, $\pi_{i}<\bar{\pi} \Rightarrow T_{i} \geq 0$; each $i$ with pre-tax income strictly larger than average may make a transfer payment, $\pi_{i}>\bar{\pi} \Rightarrow T_{i} \leq 0$; and each $i$ with pre-tax income equal to the average neither receives nor makes a transfer payment, $\pi_{i}=\bar{\pi} \Rightarrow T_{i}=0$. Note that this is a zero-sum redistribution scheme: transfers do not generate any welfare gains or losses.

\subsection{Markets with endogenous redistributive taxation}

This game has three consecutive decision-making stages: first a 'market' stage, second a 'tax competition' stage, and third an 'election' stage. In the market stage, citizens earn their pretax incomes in a double auction market just like the one described in subsection 2.1. However, in this game the tax rate is no longer exogenously given. Instead, when the market opens it is public information that $t$ is endogenously determined in the tax competition and election stages. In the tax competition stage, the ten citizens and two candidates, $j=A, B$, observe all pre-tax incomes in the market. Then, the candidates independently choose binding tax rates, $t_{j} \in[0,1]$, which are simultaneously announced to the society. In the election stage, the two tax rates, $t_{A}$ and $t_{B}$, compete in a simple majority election (with random tie breaking) where all citizens independently and simultaneously vote either for candidate $A$ or for candidate $B$ (abstention is not an option and voting is costless). The winning candidate, $w$, receives a payoff of $\sigma_{w}=25$ points and her tax rate, $t_{w}$, determines the income redistribution among citizens (as in subsection 2.1). The losing candidate, $-w \neq w$, receives a payoff of $\sigma_{-w}=15$ points and her tax rate is of no consequence. Moreover, each citizen $i$ 's final payoff (i.e., after-tax market income) is given by $\pi_{i, \operatorname{tax}} \equiv \pi_{i}+$ $T_{i}$ (as in subsection 2.1).

\subsection{Markets with lobbying and endogenous redistributive taxation}

This game has four decision-making stages. The only difference with the game described in subsection 2.2 is that a 'lobbying' stage is added in-between the market and tax competition stages. In the lobbying stage, all citizens have the opportunity to transfer points to the candidates. Specifically, they independently choose and simultaneously submit a pair of lobbying transfers $\left(l_{i \rightarrow A}, l_{i \rightarrow B}\right)$, where $l_{i \rightarrow j}$ denotes the amount sent by citizen $i$ to candidate $j$ 
and $l_{i} \equiv l_{i \rightarrow A}+l_{i \rightarrow B}$ denotes $i$ 's total amount sent. Any pair of lobbying transfers is feasible, with the only restriction that $l_{i} \in\left[0, \pi_{i}\right]$. Importantly, these transfers do not change the decision space of citizens or candidates in the next stages. In particular, candidates have no obligation towards citizens who transfer points. Then, each citizen $i$ 's final payoff is given by $\pi_{i, t a x, l o b b y} \equiv \pi_{i}+T_{i}-l_{i}$, implying that transfers are not tax deductible. Each candidate $j$ 's payoff is given by $\sigma_{j L} \equiv \sigma_{j}+L_{j}$, where $L_{j} \equiv \sum_{i=1}^{10} l_{i \rightarrow j}$ denotes the sum of transfers that $j$ receives from all citizens.

\section{Theoretical predictions}

Here, we present theoretical predictions for our games.

\subsection{Markets with exogenous redistributive taxation}

In this subsection, we derive predictions for the double auction market with exogenous redistributive taxation. We first conduct a static analysis, and examine dynamic market behavior thereafter. For our static analysis, we use the intersection of market supply and demand curves to determine equilibrium quantities and prices (see Figure 1). This gives our first prediction:

Prediction 1 (Static market equilibrium): Independent of redistributive taxation, $t \in[0,1]$, any market equilibrium is efficient (that is, yields maximum possible welfare of 238 points) and involves $q^{*}=7$ transactions at any market price $p^{*} \in\{48, \ldots, 52\}$. Compared to the average equilibrium income of 23.8 points, prior to redistribution, this results in a rich minority of four citizens with above-average income (citizens S1, S2, B1, and B2) and a poor majority of six citizens with below-average income (citizens S3, $S 4, S 5, B 3, B 4$, and B5). ${ }^{9}$

\footnotetext{
${ }^{9}$ For example, using the median equilibrium market price, $p^{*}=50$, yields the following income distribution: 52 , 46, 40, and 34 points for the rich citizens B2, S2, B1, and S1, and 17, 14, 12, 10, 7, and 6 points for the poor citizens B3, S3, B4, S4, B5, and S5.
} 
This follows directly from Figure 1. A maximum possible welfare or aggregate income ${ }^{10}$ of 238 points implies that sellers S1 and S2 and buyers B1 and B2 each trade their first and second units, and sellers S3, S4, and S5 and buyers B3, B4, and B5 each trade their first units (henceforth, we refer to these units as 'efficient units' and to the remaining units as 'inefficient units'). Moreover, in equilibrium, the average income per unit is $11.9(=238 / 20)$ points. Depending on the equilibrium market price, eight or nine out of twenty units (fourteen efficient units) earn more than average and hence are taxed (see Figure 1), while all other units receive taxes. Notably, because redistributive taxes are calculated as a percentage of market income, in our static analysis there are no inward shifts in the supply and demand curves-hence, no deadweight losses (cf. Rosen and Gayer 2007; Ruffle 2005).

We now analyze dynamic market behavior. Compared to the benchmark of maximum possible welfare, there are two sources of market inefficiency. First, inefficiencies arise if a transaction matches an inefficient unit with an efficient unit from the 'other side' of the market. For example, an inefficient trade occurs if seller S1 posts a price of 35 points for her first unit, and buyer B3 accepts this price for her second unit. Second, inefficiencies arise if an efficient unit is not traded within the market period. At one extreme, if no one trades any units, the market generates zero welfare (or 0\% efficiency) and, at the other extreme, if everyone trades all of their units, the market produces welfare of 193 points (or 81.1\% efficiency). ${ }^{11}$

\footnotetext{
10 We use the terms 'welfare' and 'aggregate income' synonymous throughout the paper. Moreover, we say that the market is efficient if it yields maximum possible welfare; the degree of efficiency in percentage is calculated as (actual welfare/maximum possible welfare) $\times 100$.

11 Note that any transaction increases welfare, but only trading paths that include all efficient units and no inefficient units yield $100 \%$ efficiency. Moreover, two of the standard trading rules already limit the possibility of inefficiencies. First, no transaction can match two inefficient units because of the requirement that $p_{i k} \geq c_{i k}$ for sellers and $p_{i k} \leq v_{i k}$ for buyers. Second, each trader must first trade her first unit (which contributes more to welfare than the second unit). Note that we conjecture subjects would obey both rules even if not made explicit.
} 
Next, we discuss in turn the cases without and with redistributive taxation. Typically, experimental double auction markets where $t=0$ yield efficiencies very close to $100 \%$ (e.g., Davis and Holt 1993; Kagel and Roth 1995). What kind of market behavior avoids the inefficiencies described above? The most important trading pattern in this respect is that sellers (buyers) start posting prices from above (below) the equilibrium price range, and adjust prices downwards (upwards) if no match with the other side of the market is found. In this way, only efficient units can be traded-roughly at equilibrium prices, if sellers and buyers seek as high as possible market incomes. ${ }^{12}$ However, recall that they are not informed about others' costs and values, from which they could derive the equilibrium price range, and hence must rely on their subjective beliefs about this range. Nonetheless, if they post prices 'aggressively' - that is, well above costs for sellers and well below values for buyersand make adjustments in small steps, inefficiencies can be substantially avoided. Moreover, note that if pricing is monotonic-that is, lower-cost units are priced lower than higher-cost units and higher-value units are priced higher than lower-value units-welfare is further promoted because efficient units are more likely to be traded early and, hence, inefficient transactions are less likely. Indeed, aggressive and monotonic posting of prices has been observed in experiments (e.g., Smith 1962; Davis and Holt 1993; Kagel and Roth 1998) and, therefore, we expect the same for our double auction market without redistributive taxation. ${ }^{13}$

Does market behavior change in the presence of redistributive taxation? If rational traders expect tax rates to be strictly positive, $t>0$, then a seller's minimum willingness to accept may exceed her respective unit's cost and a buyer's maximum willingness to pay may be smaller than her respective unit's value. As a consequence, the supply and demand curves shown in Figure 1 may shift inwards-at least temporarily—and sellers and buyers may post

\footnotetext{
12 That is, unless there are so few acceptances that sellers and buyers end up adjusting their prices below and above the equilibrium price range.

13 In some experimental double auction markets, transaction prices tend to come from above or below the market price (range). We conjecture one of the reasons to be subjective beliefs about others' costs and values, which may vary for sellers and buyers and across different shapes of supply and demand curves.
} 
prices more aggressively than when there is no redistribution. This is because they take into account the possibility that their own transaction may prohibit the transaction of more welfare-enhancing, lower-cost and higher-value units by others (for a detailed analysis, see Appendix A). Specifically, the after-tax market incomes of sellers and buyers consist of a 'private' component-that is, the non-taxed part of their market incomes-and a 'welfare' component received from redistribution. At one extreme, if $t=0$, then they always have an incentive to trade both of their units, because this increases their market incomes. At the other extreme, if $t=1$, then they only have an incentive to trade efficient units-at any feasible price-but never inefficient units (of course, in our setup sellers and buyers must form subjective beliefs about whether or not they possess efficient units). Note the important tradeoff: although trading an inefficient unit always increases a trader's private component, this-depending on the tax rate-may be outweighed by a decrease in her welfare component, if an efficient unit that is sufficiently welfare-enhancing can no longer be traded. Precisely for the reason of covering this potential loss from trading, they may demand a 'risk premium'-that is, increase their minimum willingness to accept and decrease their maximum willingness to pay. Hence, risk premiums yield inward shifts in the supply and demand curves. ${ }^{14}$ Because the importance of the welfare component relative to the private component increases in the tax rate, a higher $t$ should result in stronger inward shifts. Moreover, if the sellers' (buyers') beliefs about their own costs (values) compared to those of others are monotonic - that is, preserve the ranking of actual costs (values) in the marketthese shifts should be stronger for units with larger costs (smaller values). The next prediction summarizes our arguments:

\footnotetext{
${ }^{14}$ In principle, the supply and demand curves may also shift outwards. However, this is excluded by our trading rule that units must not be sold below costs and bought above values.
} 
Prediction 2 (Market dynamics): Posted prices are at least as aggressive for higher than for lower tax rates, $t$ (that is, sellers and buyers tend to post higher and lower prices, respectively, if tax rates are higher). If beliefs about their own costs and values relative to those of others are monotonic (that is, preserving the ranking of actual costs and values in the market), then this tendency is stronger for higher-cost sellers and lower-value buyers.

\subsection{Tax competition and voting}

Under the assumption that Prediction 1 holds-in particular, that there is a rich minority and a poor majority prior to taxation-we can simplify our analysis and derive subgame perfect equilibria for the tax competition and election stages. As a refinement, we use iterated elimination of weakly dominated strategies. We first analyze the voting stage and, thereafter, the tax competition stage.

Prediction 3 (Subgame perfect equilibrium for endogenous taxation without lobbying): If Prediction 1 holds, then there is a unique subgame perfect equilibrium in weakly dominant strategies of the tax competition and election stages, in which both candidates choose full redistribution, $t_{A}^{*}=t_{B}^{*}=1$ and all citizens randomize their vote between the two candidates. ${ }^{15}$

Proof: We use iterated elimination of weakly dominated strategies. Then, in the voting stage, each citizen votes sincerely for her preferred candidate: if $t_{j}<t_{-j}$ the four rich citizens vote for $j$ and the six poor citizens vote for $-j$, and if $t_{j}=t_{-j}$ all citizens randomize their votes between the two candidates. This is because voting sincerely yields citizen $i$ a

\footnotetext{
15 In elections with two distinct alternatives and compulsory, simple majority voting, there is a unique Nash equilibrium in weakly dominant strategies where everyone votes sincerely for her preferred alternative and, hence, the majority wins. Allowing for insincere voting (dramatically) increases the number of Nash equilibria where both majorities and minorities can win. In experiments, relatively few insincere votes are observed (e.g., McKelvey and Ordeshook 1990). If voting is costly, majorities win more often and the likelihood increases in the difference between the sizes of the majority and minority (see Großer and Schram 2009; Levine and Palfrey 2007).
} 
higher payoff than voting insincerely in cases where her vote is pivotal (that is, when there are four votes for one candidate and five votes for the other candidate by the nine other citizens), and her payoff does not depend on her vote in all other, non-pivotal cases. Thus, voting sincerely weakly dominates voting insincerely. Each candidate anticipates the citizens' equilibrium decisions in the voting stage. Then, in the tax competition stage the two candidates choose $t_{A}^{*}=t_{B}^{*}=1$. This tax rate weakly dominates any lower tax rate $t_{j}^{\prime}<1$, because $t_{j}^{\prime}$ yields the same payoff for $j$ as $t_{j}^{*}$ if $t_{-j}<t_{j}^{\prime}$; a lower expected payoff than $t_{j}^{*}$ if $t_{-j}=t_{j}^{\prime}$; and a lower payoff than $t_{j}^{*}$ if $t_{-j}>t_{j}^{\prime}$

\subsection{Lobbying}

Next, we analyze our game with lobbying. We derive the following prediction.

Prediction 4 (Subgame perfect equilibrium for endogenous taxation with lobbying): If Prediction 1 holds, then there is a unique subgame perfect equilibrium in weakly dominant strategies of the lobbying, tax competition, and election stages, in which no citizen transfers any money amount to the two candidates, $l_{i}^{*}=0$ for all $i$, both candidates choose full redistribution, $t_{A}^{*}=t_{B}^{*}=1$, and all citizens randomize their vote between the two candidates.

Proof: Building on the proof of Prediction 3, citizens anticipate the equilibrium decisions in the tax competition and voting stages, which are independent of any (nonbinding) transfers by citizens, $\left(l_{i \rightarrow A}, l_{i \rightarrow B}\right)$. Thus, lobbying only decreases a citizen's payoff and all $i$ choose $l_{i}^{*}=0$

\subsection{Alternative predictions}

A variety of 'behavioral' influences may affect our previous predictions. Hence, we briefly discuss some plausible alternative predictions.

First, many experiments have shown that decisions are prone to systematic mistakesthat is, are stochastic with more lucrative decisions being made more often (as in the quantal response equilibrium of McKelvey and Palfrey 1995, 1998). As a consequence, to some extent, we anticipate deviations from our Predictions 1, 3, and 4. For example, candidates 
may not always choose tax rates of one and voters may not always vote sincerely (and more so for smaller differences in both tax rates).

Second, there is a bulk of evidence that payoff dominant outcomes and marginal incentives matter for decision making in ways not explained by Nash equilibrium (e.g., Isaac and Walker 1988). For example, in our double auction market with redistributive taxation, two decisions need to be distinguished: the decisions on whether or not to trade, and if yes, on pricing. The marginal income of a traded unit is decreasing in the tax rate by a factor $t \times \frac{n-1}{n}$ if it earns more than average, and it is increasing by this factor if it earns less than average. ${ }^{16}$ This may result in less pricing effort for above-income units when higher tax rates are anticipated, potentially spurring transaction and price volatility that result in inefficiencies. By contrast, the marginal incentive to trade an efficient (inefficient) unit is increasing (decreasing) in the tax rate, which promotes efficiency. Moreover, candidates have constant marginal incentives (i.e., 10 points) to win the elections. However, citizens can manipulate these incentives through lobbying-that is, they can shoulder some of the candidates' risks from moving away from zero-tax rates by transferring money to them. In this respect, the success of lobbying depends on whether or not the rich minority can provide candidates with sufficiently high incentives to deviate in their favor, in spite of potential counteractive lobbying of the poor. Note that if both candidates manage to coordinate on the same lower tax rates, they and the rich can achieve payoff dominant incomes, on average. ${ }^{17}$

Third, fairness concerns play an important role in many decision making situations (e.g., as in models of social preferences or inequality aversion; Bolton and Ockenfels 2000, Fehr and Schmidt 1999). A particularly drastic influence of fairness concerns may occur in the double auction market, if the rich abstain from trading their efficient units in order to

16 Citizen $i$ 's after-tax income is given by $\pi_{i, \operatorname{tax}}=\pi_{i}+t\left(\bar{\pi}-\pi_{i}\right)=\pi_{i}+t\left(\frac{n-1}{n} \bar{\pi}_{-i}+\frac{1}{n} \pi_{i}-\pi_{i}\right)=\pi_{i}+t \times$ $\frac{n-1}{n}\left(\bar{\pi}_{-i}-\pi_{i}\right)$, where $\bar{\pi}_{-i}$ denotes the average pre-tax income of all citizens other than $i$. Then, $\frac{\partial \pi_{i, t a x}}{\partial \pi_{i}}=1-t \times \frac{n-1}{n}$ if $\pi_{i}>\bar{\pi}_{-i} ; 1+t \times \frac{n-1}{n}$ if $\pi_{i}<\bar{\pi}_{-i} ;$ and 1 if $\pi_{i}=\bar{\pi}_{-i}$.

17 For example, the collusion of the candidates and the rich may be triggered by reciprocity (e.g., Dufwenberg and Kirchsteiger 2004; Falk and Fischbacher 2006). 
punish high tax rates-for example, because of spitefulness (Levine 1998) or because they feel entitled to higher shares of the welfare (Bosman and van Winden 2002). As another example, in elections full redistribution (see our Predictions 3 and 4) may be reinforced if some inequality-averse rich citizens vote for higher tax rates, alongside with the poor.

Obviously, many of the 'behavioral' influences are interactive, giving the same or opposing incentives. Admittedly, distinguishing these influences in our experiment seems to be a difficult task. However, it is nonetheless important to understand why potential deviations from our Predictions 1 to 4 may occur, and if substantial, to elaborate further on our alternative predictions.

\section{Experimental design}

The computerized experiment was run at the Economics Laboratory of the University of Cologne.18 136 students participated in 6 sessions of 20 or 24 subjects. Each session lasted about two hours (see the online appendix for instructions). Subjects earned an average of $€ 27.00$, which included a show-up fee of €2.50.

In each session, the 20 or 24 subjects were randomly divided into two societies of ten citizens or ten citizens and two candidates. There was no interaction of any kind between subjects in different societies, and this was public information. Given that we do not know the structure of the correlations across observations, we treat the society as the independent unit of observation, unless otherwise noted. Hence, each session provides us with two independent observations.

The experiment consisted of four treatments, all of which started with a computerized double auction market. They varied with respect to whether redistributive taxes were determined exogenously or endogenously and whether or not lobbying was allowed. Market0 and Market-1 used exogenous tax rates of 0 and 1, respectively (see subsection 2.1); No Lobbying used endogenous tax rates through tax competition and elections (see subsection 2.2); and Lobbying used endogenous tax rates and, in addition, provided citizens with the

\footnotetext{
18 We used z-Tree (Fischbacher 2007) for programming the experimental software and ORSEE (Greiner 2004) for recruiting subjects.
} 
Table 1 - Summary of treatments and parameters

\begin{tabular}{lcccc}
\hline \hline Treatment & Sellers/Buyers/Candidates & Tax rate & Lobbying & \# societies \\
\hline Market-0 & $5 / 5 / 0$ per society & 0 & No & 4 \\
Market-1 & $5 / 5 / 0$ per society & 1 & No & 4 \\
No Lobbying & $5 / 5 / 2$ per society & endogenous & No & 8 \\
Lobbying & $5 / 5 / 2$ per society & endogenous & Yes & 8 \\
\hline \hline
\end{tabular}

opportunity to transfer money amounts to the candidates prior to tax policy choices (see subsection 2.3). In a within-subjects design, we compare Market-0 to Market-1 and No Lobbying to Lobbying, where 10 periods of one treatment were followed by 10 periods of the other treatment (to control for order effects, we reversed the sequence of both treatments across sessions). At the beginning of each session, subjects were informed that there will be two parts with 10 periods each, but they were not given the instructions for the second part until the first part had finished. To some extent, depending on the observed tax rates in No Lobbying and Lobbying, we can also make comparisons between subjects for these two treatments and Market- 0 and Market-1.

At the beginning of each session, subjects were randomly assigned the roles of sellers and buyers (and of two candidates in No Lobbying and Lobbying) and the costs and values of their two units of the good (see Figure 1). None of these assignments changed during the entire session, and subjects were informed about this. In each of the $2 \times 10$ periods, the market was open for 2 minutes. ${ }^{19}$ Finally, it was public information that everyone in the society will be fully informed of: each citizen's pre-tax and after-tax market income; in the Lobbying treatment, each citizen's money transfers to the two candidates; each candidate's tax rate; and their vote tallies in the elections. Note that the identities of specific citizens and candidates were never revealed to other subjects. Table 1 summarizes our treatments and parameters.

\footnotetext{
19 To familiarize subjects with the trading rules and software, we conducted three unpaid double auction markets before the first part started.
} 


\section{Experimental results}

The presentation and analysis of our data is organized as follows. We begin by analyzing observed pre- and after-tax market earnings (subsection 5.1). Thereafter, we examine in more detail market behavior (5.2), efficiency (5.3), lobbying behavior (5.4), and finally, voting and candidate behavior (5.5). Where appropriate, we confront the results with our theoretical and alternative predictions.

\subsection{Pre- and after-tax market earnings}

Figure 2 shows observed mean pre- and after-tax market earnings for each treatment and seller and buyer type. ${ }^{20}$ For comparison, it also gives the pre-tax earnings ( $\times$ signs) and aftertax earnings (+ signs) derived from our Predictions 1, 3, and 4.21

In all treatments, the observed mean levels and distributions of pre-tax earnings are very similar to those in Prediction 1 (compare the $\times$ signs and the light blue bars in Figure 2). As a consequence, in almost every period there is a rich minority of four subjects and a poor majority of six subjects (100.0\% of all cases in Market-0; $95.00 \%$ in Market-1; $98.75 \%$ in No Lobbying; and 97.50\% in Lobbying). Moreover, in line with Predictions 3 and 4, virtually full egalitarian after-tax market earnings are not only observed in Market-1 but also in our No Lobbying and Lobbying treatments (compare the + signs and the dark green bars). This gives:

Experimental result 1 (Earnings distributions): In all treatments, market earnings generate a rich minority and a poor majority. When redistribution is endogenous, welfare is virtually fully egalitarian.

Figure 2 also indicates that the number of transactions and their prices must be roughly determined by the intersection of the induced demand and supply curves (see Prediction 1 and Figure 1) and that the winning tax rates in the No Lobbying and Lobbying

\footnotetext{
20 The after-tax market earnings in the Lobbying treatment include transfers to candidates and, hence, are not the final earnings of traders.

21 We calculated the predicted pre-tax earnings using the median equilibrium price of 50 points.
} 

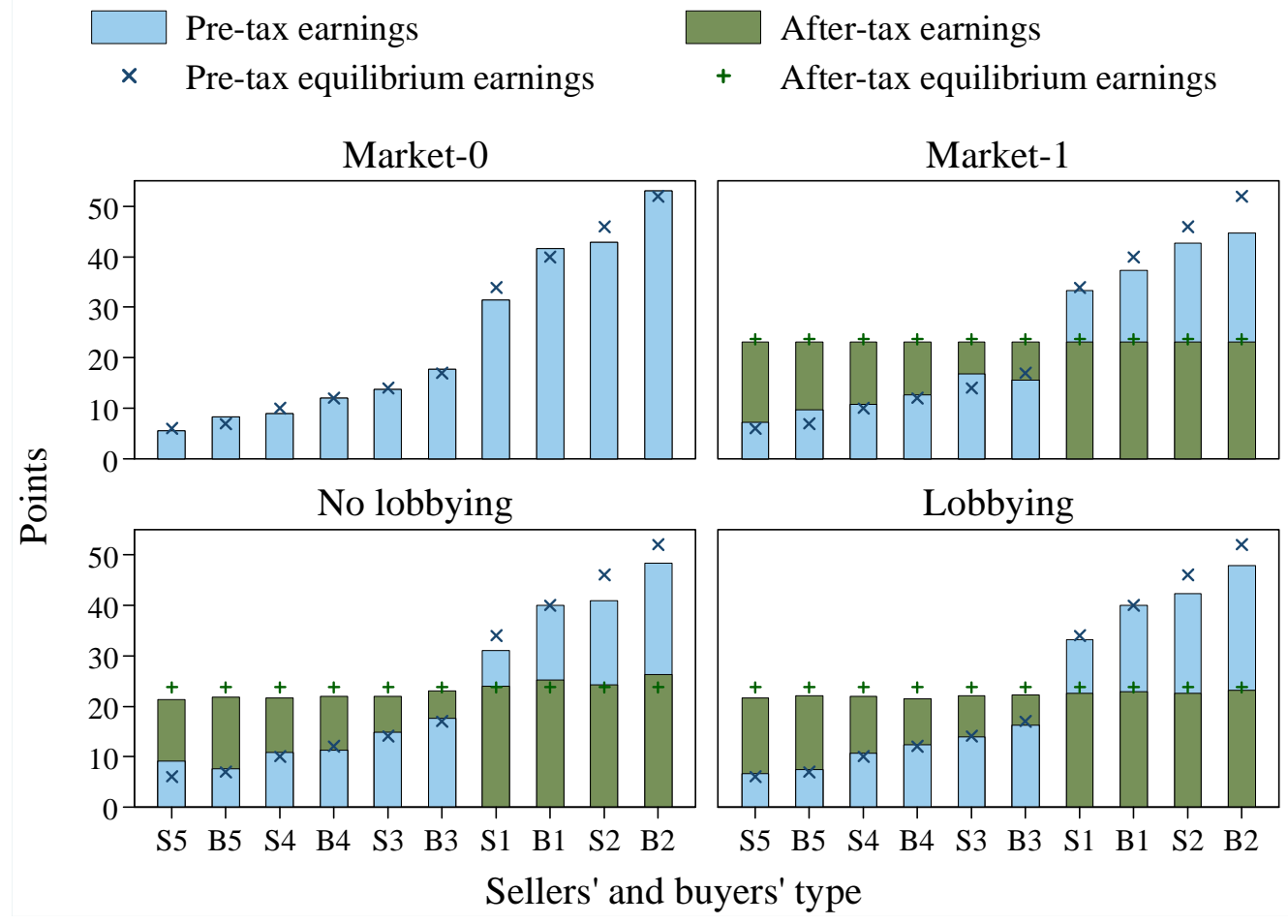

Figure 2 - Pre- and after-tax market earnings

Note: The figure shows, for each treatment, the pre- and after-tax market earnings for each buyer type (B1,..., B5) and seller type (S1,..., S5). It also gives the pre- and after-tax earnings derived using equilibrium quantities, prices, and tax rates of $q^{*}=7, p^{*}=50$, and $t^{*}=1(t=0$ in Market- 0 , where pre- and after-tax earnings are identical, and $t=1$ in Market-1).

treatments must be very close to one (see Predictions 3 and 4). Notably, the dramatic redistribution does not markedly decrease efficiency: realized mean earnings are generally only slightly lower than in the efficient market equilibrium. Below, we discuss the observations from Figure 2 in more detail.

\subsection{Market behavior}

Market outcomes are summarized in Figure 3. For each treatment and period it shows: the mean number of transactions (right-hand axis), the mean transaction price (left-hand axis), and the mean market efficiency in percentage (see footnote 10; also left-hand axis). The vertical bars correspond to one standard deviation above and below the respective mean (periods with no vertical bars are due to no variation). Table 2 provides further statistics, 


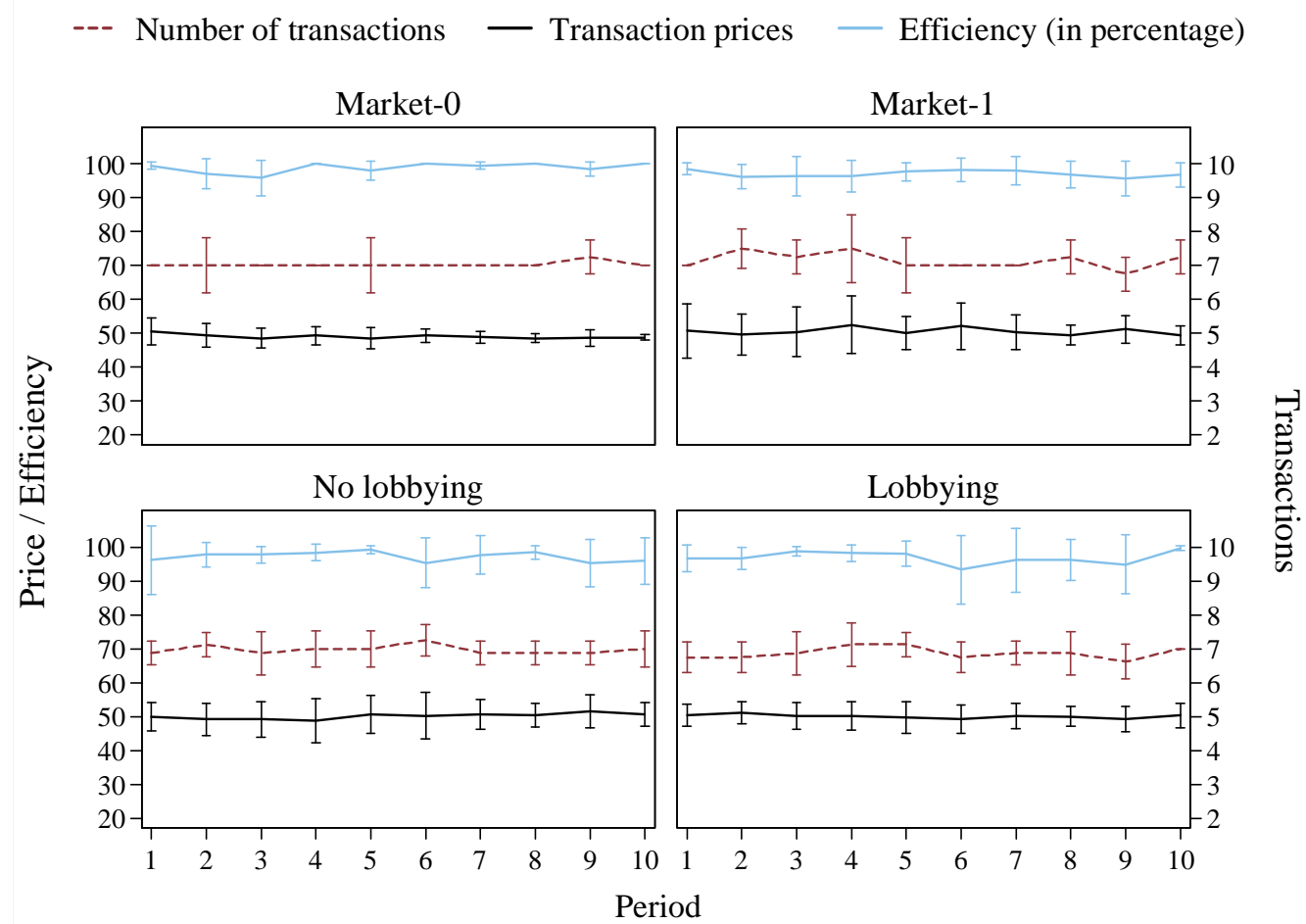

Figure 3 - Double auction markets

Notes: The figure shows, for each period per treatment, the mean number of transactions (red), mean transaction price (black), and mean efficiency (light blue; measured as realized market earnings as a percentage of maximum possible market earnings). Vertical bars correspond to +/- one standard deviation.

including the mean ask-bid spread, that is, the difference in posted prices of sellers ('asks') and buyers ('bids').

In all treatments, the observed mean numbers of transactions are very close to the market equilibrium of $q^{*}=7$ and quite stable across periods (see Prediction 1 and Figure 3). Statistically, averaged over all periods, they are with 7.03, 7.15, and 6.98 not significantly different from seven in Market-0, Market-1, and No Lobbying ( $p>0.36$; see Table 2).22 In

22 Unless otherwise noted, we throughout test treatment effects by comparing the coefficients of treatment dummy variables, which are estimated using OLS regressions and robust standard errors (White, 1980). As mentioned earlier, we use society as the unit of independent observation and apply society random effects to control for unobservable characteristics. For variables that are calculated every period, such as market transactions, we control for potential time trends and order effects by including unconditional period fixed effects. For variables that are calculated every 10 periods (i.e. every part), such as the mean standard deviation of 
Table 2 - Market outcomes

\begin{tabular}{|c|c|c|c|c|c|}
\hline & Market-0 & Market-1 & No lobbying & Lobbying & Zero intelligence \\
\hline \multicolumn{6}{|l|}{ \# of transactions } \\
\hline Mean & 7.03 & 7.15 & 6.98 & 6.88 & 6.97 \\
\hline Std. dev. & 0.31 & 0.40 & 0.37 & 0.45 & 0.89 \\
\hline$\%$ equal to 7 & $87.50 \%$ & $77.50 \%$ & $80.00 \%$ & $75.00 \%$ & $50.84 \%$ \\
\hline \multicolumn{6}{|l|}{ Price } \\
\hline Mean & 49.04 & 50.58 & 50.16 & 50.08 & 51.17 \\
\hline Std. dev. & 2.42 & 5.62 & 4.91 & 3.72 & 12.97 \\
\hline$\%$ in $[48,52]$ & $69.78 \%$ & $55.21 \%$ & $49.43 \%$ & $51.26 \%$ & $17.45 \%$ \\
\hline \multicolumn{6}{|l|}{ Ask-bid spread } \\
\hline Mean & 10.92 & 15.01 & 12.98 & 11.88 & 10.41 \\
\hline Std. dev. & 4.55 & 4.51 & 6.57 & 4.47 & 4.13 \\
\hline \multicolumn{6}{|l|}{ Efficiency } \\
\hline Mean & 98.81 & 97.04 & 97.21 & 96.89 & 92.74 \\
\hline Std. dev. & 2.42 & 3.33 & 3.07 & 4.53 & 8.06 \\
\hline$\%$ equal to 100 & $75.00 \%$ & $47.50 \%$ & $55.00 \%$ & $57.50 \%$ & $20.47 \%$ \\
\hline
\end{tabular}

Lobbying, the mean number of transactions is with 6.88 weakly significantly lower than seven $(p=0.08)$, but the observed difference is very small. Moreover, we do not find significant differences in mean standard deviations between any of the treatments $(p>0.19$; see Table 2). ${ }^{23}$

Figure 3 also shows that the observed mean transaction prices all fall within the equilibrium price range of $[48,52]$ points (see Prediction 1 ). However, it also reveals some differences in price volatility across treatments. This can be seen more clearly when looking at the mean standard deviations in prices in Table $2 .{ }^{24}$ Price volatility is, with a standard deviation of 2.42, lowest in Market-0, followed by 3.72, 4.91, and 5.62 in Lobbying, No Lobbying, and Market-1. Statistically, while the standard deviations are not significantly

the number of transactions, we also include part dummy variables. This approach allows us to fully exploit the panel structure of our data.

23 We calculated the standard deviation in the number of transactions across the ten market periods for each society, and then took the mean of the standard deviations across societies per treatment.

24 We calculated the standard deviation in prices for each market period per society, and then took the mean across all periods and societies per treatment. 
different from each other in Market-1 and No Lobbying ( $p=0.51)$, for both treatments they are significantly higher than in Market-0 $(p<0.01)$ and weakly significantly higher than in Lobbying $(p<0.07)$. Moreover, the standard deviation in Lobbying is weakly significantly higher than the one in Market-0 ( $p=0.09)$.

Interestingly, and consistent with Prediction 2, we do see differences in posted prices between treatments. Table 2 shows a larger spread between mean asks and bids in Market-1 than in Market-0 (15.01 vs. 10.92; the difference is statistically significant, $p<0.01$ ). Hence, subjects do indeed trade more aggressively with full redistribution than with zero-tax rates. Moreover, though the ask-bid spread is also higher in No Lobbying and Lobbying than in Market-0, the differences are not significant (12.98 and 11.88 vs. $10.92 ; p>0.24) .{ }^{25}$

We further test these results by examining who exactly causes the increased difference in posted prices between both sides of the market in Market-1 compared to Market-0. To do so, we utilize the within-subject design between these two treatments to run regressions with mean asks or mean bids as the dependent variables. As independent variables, we use the costs or values of the traded units, and interact this with a treatment dummy variable. ${ }^{26}$ As one would expect, there is a strong positive relationship between asks and the cost of the unit ( $p=0.01)$ and bids and the value of the unit ( $p=0.01)$. Comparing Market- 0 and Market-1, we find that asks are significantly higher in Market-1 for units with costs greater than 18 points - the lowest cost in the market-(Wald tests, $p<0.02$ ) and that bids are significantly lower in Market-1 for units with values smaller than 67 points-the fourth highest value in the market-(Wald tests, $p<0.05$ ). Thus, the observed higher askbid spread in Market-1 is due to some buyers systematically bidding less and some sellers systematically biding more compared to when there is no redistribution, which is consistent with our Prediction 2. Moreover, also consistent with Prediction 2 is the observation that the

\footnotetext{
25 Compared to Market-1, the ask-bid spread is weakly significantly different in Lobbying $(p=0.08)$ but not in No Lobbying $(p=0.29)$.

${ }^{26}$ In each society, mean asks and bids were calculated for each period and unit (10 seller and 10 buyer units). We ran a separate OLS regression for sellers and buyers. Given that costs and values almost identify specific subjects in a society, we used subject random effects and include unconditional period and society fixed effects.
} 
treatment difference occurs for goods that are more likely to produce an efficiency loss (i.e., units with low values or high costs).

Although the higher ask-bid spread observed in Market- 1 compared to Market- 0 is in line with our Prediction 2, it could be argued that that is the result of subjects trading more carelessly due to lower marginal incentives from trading (see our alternative predictions in subsection 3.4). To better evaluate the degree to which this is a consequence of noisy decision making, we provide a random benchmark in the next subsection.

We find little support for other alternative predictions. In particular, we do not see evidence of rich subjects abstaining from trading when highly taxed (e.g., because of spitefulness). For example, in Market-1 the four rich subjects trade $99.39 \%$ of the six units that have an important impact on efficiency-that is, the three lowest cost and three highest value units, which in equilibrium account for $70.59 \%$ of all market earnings and $97.67 \%$ of the rich's pre-tax earnings. This percentage does not look much different in No Lobbying and Lobbying, where the rich trade $98.13 \%$ and $96.88 \%$ of their six most efficient units (for comparison, in Market-0 they trade $98.75 \%$ of these units).

The following result summarizes our findings from this subsection:

Experimental result 2 (Market behavior): Market behavior is generally quite similar across treatments, but price volatility and ask-bid spreads are markedly higher with exogenous full redistribution.

\subsection{Zero-intelligence trading}

In the previous subsections, we have shown that-in spite of drastically different tax rates across treatments-observed mean market outcomes are roughly consistent with our Prediction 1. To what extent can this strong result be attributed to the double auction market' mechanism itself, and to what extent to the market behavior of subjects? In particular, Gode and Sunder (1993) argue that the trading rules of the double auction market yield near-equilibrium outcomes even with 'zero-intelligence' traders-that is, robots that randomly post and accept prices within the bounds of the rules. In this sense, it is interesting to compare our predictions and experimental results with a zero-intelligence benchmark. If 
high tax rates induce subjects to trade carelessly and this translates to more random behavior, then the subjects' behavior in Market-1 should be similar to that of robot traders. To perform this comparison, we follow Gode and Sunder (1993) and run simulations using our specific parameters and trading rules (see Appendix B for a more detailed description of the procedures). For example, we use the same number of sellers and buyers and the same distribution of costs and values as shown in Figure 1. The results of our simulations are presented in the last column of Table 2 .

Table 2 shows that even though robot traders post and accept prices randomly, the mean number of transactions is practically equal to the equilibrium number of seven, and the mean price of 51.17 falls within the equilibrium range of $[48,52]$ points. However, robot traders produce much higher price volatility than our subjects (i.e., a standard deviation of 12.97 vs. 5.52, 4.91, 3.72, and 2.42 in Market-1, No Lobbying, Lobbying, and Market-0). As a consequence, only $17.45 \%$ of transactions in our simulations are actually made at equilibrium prices (as compared to $69.78 \%$ in Market-0 and around half in the other treatments). Compared to prices, the number or transactions look more similar between robots and subjects, although once again, they tend to vary more for the zero-intelligence traders. Moreover, Table 2 shows that our simulations with robot traders yield a mean askbid spread of around the same magnitude as Market-0 does. Both spreads are the lowest (10.41 and 10.92), followed by 11.88, 12.98, and 15.01 in Lobbying, No Lobbying, and Market-1. In summary, while robot pricing yields substantially higher price volatility than in our four treatments, differences in volatilities are more moderate with respect to the number of transactions and ask-bid spreads.

The most important differences in market behavior observed between our experimental treatments are the higher price volatility and ask-bid spread in Market- 1 . The zero-intelligence simulation results suggest that the higher ask-bid spread is not due to random posting of prices, but to a systematic change in market behavior-the largest difference in spread is with 4.60 (4.09) points found between Market-1 and our simulations (Market-0). In light of our simulation results, what are the consequences of the higher askbid spread in Market-1? We conjecture that the more aggressive posting of prices prevents 
even higher price volatility, as the one produced by robot traders. Note that similar things as for Market-1 seem to hold for Lobbying, though to a smaller extent. Moreover, from comparing price volatility and ask-bid spreads between our No Lobbying and Lobbying treatments, we also conjecture that lobbying may have a small influence on decreasing the mean ask-bid spread (12.98 vs. 11.88) and, in this way, decrease price volatility (4.91 vs. 3.72 standard deviations).

\subsection{Efficiency}

The highest mean market efficiency is observed in Market-0 where subjects achieve $98.81 \%$ of the maximum earnings (see Table 2). At around 97\%, efficiency is almost two percentage points lower in the three other treatments. If we test for statistical differences, we observe that the mean efficiency in Market-0 is significantly higher than in Market-1 ( $p=0.01)$, but we do not find a significant result for the other comparisons $(p>0.25)$. Importantly, double auction markets in our experimental treatments are between four to six percentage points more efficient than in the zero-intelligence simulations, which have a mean efficiency of 92.74\%. Hence, exogenously increasing tax rates from zero to one seems to negatively affect market efficiency (compare Market-1 and Market-0). However, full redistribution does not destroy all market incentives, as evidenced by a substantially higher efficiency in Market-1 compared to the simulations with robot traders who randomly post and accept prices. This gives:

Experimental result 3 (Efficiency): Market efficiency ranges from 97 to 99\% and is highest without redistribution. In all treatments, efficiency is between 4 to 6 percentage points higher than in our simulations with robot traders that post and accept prices randomly.

\subsection{Lobbying}

Figure 4 gives for each period in our Lobbying treatment the observed mean lobbying transfers of citizens in points per candidate (left panel) and per citizen (right panel), distinguishing between transfers from the rich and poor subjects. There are substantial transfers in the first period, where each candidate receives an average of 12.00 and 4.81 


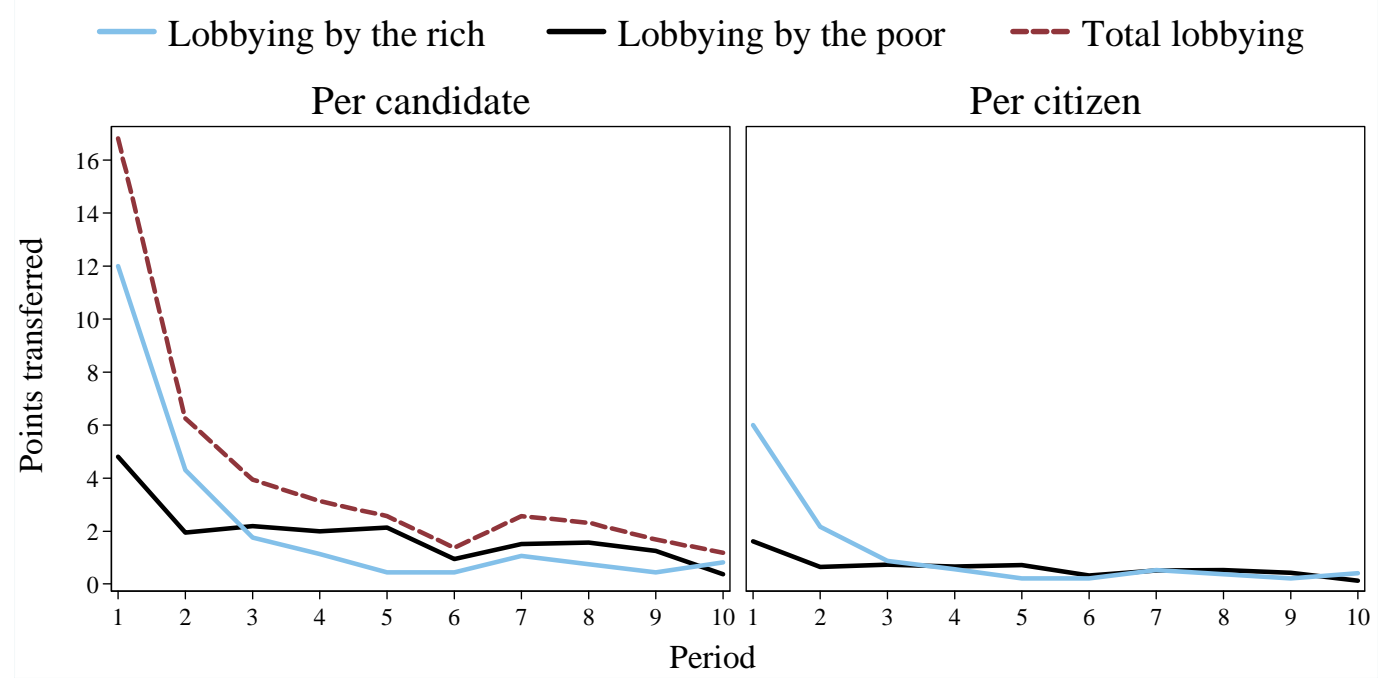

Figure 4 - Mean lobbying transfers to candidates

points from the rich and poor. However, transfers drop sharply in the second period, and continue to decrease until each candidate receives approximately a total of two points per period from around the fifth period onward. Accordingly, while lobbying behavior does not initially conform to the predicted zero transfers, it is not too far off in later periods (see Prediction 4). Note that the percentage of welfare spent on money transfers in our experiment is very low, which also holds for the percentage of GDP spent on lobbying in the United States.

In Table 3, we examine whether there is support for our alternative prediction that candidates respond to lobbying transfers by citizens. It shows that the mean tax rate chosen by the candidates does indeed depend on the difference of transfers between the rich and the poor. When this difference is zero or negative (i.e., the rich lobby on average less than the poor), mean tax rates are very high. By contrast, when the difference is positive (i.e., the rich transfer on average more than the poor), mean tax rates decrease by about twenty percentage points. This negative relationship is statistically significant (Spearman rank correlation coefficient $\rho=-0.36, p=0.01$ ).

But if candidates respond to lobbying, it is reasonable to ask why do we observe virtually full redistribution (see Figure 2)? The main reason is that rich subjects do not consistently transfer more points to the candidates than the poor subjects do. Recall that, if both candidates have the same probability of winning, each candidate has expected earnings 
Table 3 - Effect of lobbying on tax rates

\begin{tabular}{lccccc}
\hline \hline & \multicolumn{6}{c}{ Transfers from rich citizens minus transfers from poor citizens } \\
& -5 or less & $(-5,0)$ & 0 & $(0,5)$ & 5 or more \\
\hline Mean tax rate & 0.95 & 0.94 & 0.93 & 0.70 & 0.77 \\
Standard deviation & 0.08 & 0.16 & 0.20 & 0.39 & 0.28 \\
Frequency & $5.63 \%$ & $28.13 \%$ & $35.00 \%$ & $20.00 \%$ & $11.25 \%$ \\
\hline \hline
\end{tabular}

of 20 points. It follows that a transfer of at least 5 points is needed to compensate a candidate for choosing a tax rate smaller than one and putting herself at risk of losing the election. Hence, intuitively, the rich need to outspend the poor by at least 5 points per candidate. However, cases in which there is a 5-point difference in transfers between rich and poor are rarely observed in our Lobbying treatment, seemingly due to miscoordination among rich citizens. In total, there are 44 out of 80 cases in which at least one candidate receives some money from the rich and only 28 cases where both candidates get something. Of these 28 cases, there are only 4 cases where both candidates receive 5 points or more from rich citizens than from poor citizens (all 4 cases occurred in the first period). Statistically, only in the first period do rich citizens transfer significantly more than poor citizens (Wilcoxon signed-rank tests, $p=0.02$ in period 1 , else $p>0.16$ ), but even in this period the difference in transfers is not significantly different from 5 points (Wilcoxon signed-rank test, $p=0.26$ ).

There is also miscoordination among the candidates: 39 out of 80 tax rates are lower than the predicted tax rate of one (see Prediction 4). But only 12 of these cases occur in the same period. As a result, although we observe a substantial number of deviations from the predicted tax rate-in part due to lobbying and candidate responses to it-the winning tax rates are very often close to or equal to one. This is discussed in more detail in the next subsection.

We summarize the findings of this subsection in our next result: 


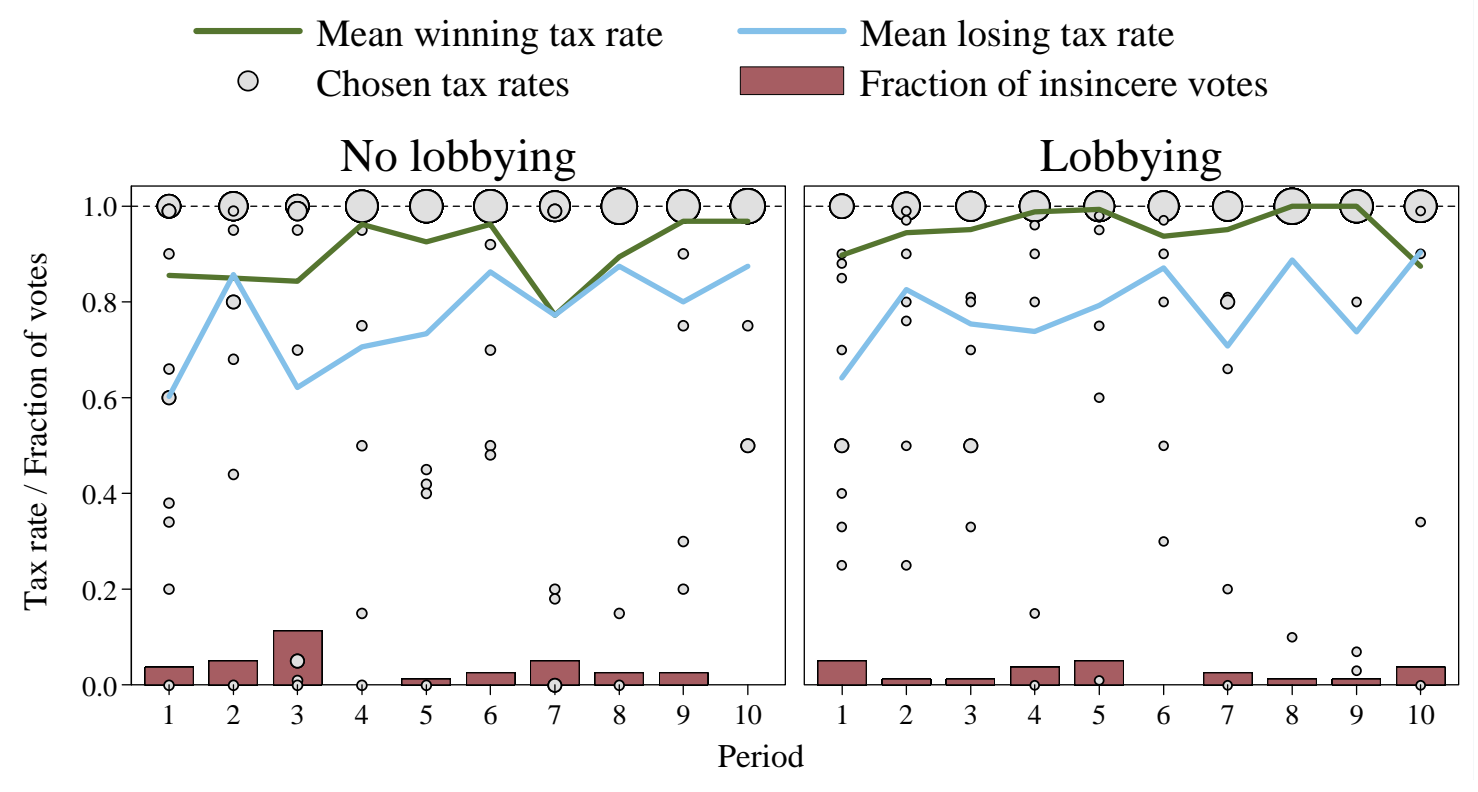

Figure 5: Elections

Note: The figure shows, for each period and treatment, the chosen tax rates (weighted by their relative frequency; circles), the mean winning and losing tax rates (dark green and light blue lines), and the fraction of insincere votes (bars).

Experimental result 4 (Lobbying): There is substantial lobbying by the rich and counteractive lobbying by the poor at the beginning, but thereafter only small amounts are transferred to the candidates. Candidates choose on average about 20\% lower tax rates when they receive more money from the rich than from the poor.

\subsection{Elections}

Figure 5 shows for each period in our No Lobbying and Lobbying treatments: the chosen tax rates weighted by their relative frequency (circles), the mean winning and losing tax rates (dark green and light blue lines), and the proportion of insincere votes (bars) - that is, votes that are contrary to a voter's pecuniary interest.

In both treatments, consistent with our Predictions 3 and 4, the observed modal tax rate is one. Full redistribution policies are chosen $65.62 \%$ and $68.13 \%$ of the time in No Lobbying and Lobbying, which results in mean winning tax rates of 0.90 and 0.95 (the winning tax rates are not significantly different between the two treatments and the same holds for the chosen tax rates; Wilcoxon-Mann-Whitney tests, $p>0.13$ ). Moreover, we 
observe only a few insincere votes: overall, $3.38 \%$ of all votes in No Lobbying and $2.50 \%$ in Lobbying (the difference between the two percentages is not significant; Wilcoxon-MannWhitney test, $p=0.33$ ). Interestingly, insincere voting is significantly more common among rich than poor subjects-possibly due to fairness concerns, although the difference in magnitude is still small (4.79\% vs. 1.64\%; Wilcoxon-Mann-Whitney test, $p=0.01$ ) -and, hence, contributes to the observation that higher tax rates almost always win. This result combined with our finding that the rich's lobbying attempts are not successful (see subsection 5.5) essentially means that money transfers constitute a pure redistribution from citizens to candidates (as in, Bernheim and Whinston 1986; Dixit, Grossman, and Helpman 1997).

We have arrived at our final result:

Experimental result 5 (Elections): In the treatments with endogenous redistribution, the mean winning tax rates are with 0.90 and 0.95 very high and citizens vote almost always sincerely.

\section{Conclusions}

We experimentally study how markets and elections interact, and in particular, how their interaction affects the generation and distribution of welfare. Based on the observation that all democracies around the world have a majority of citizens with pre-tax incomes below the average national income, we use a double auction market where, in equilibrium, market outcomes generate a rich minority and a poor majority. When we impose no redistributive taxation, our experimental results confirm the well-known effectiveness of these markets in generating efficient outcomes. Remarkably, efficiency is only about two percentage points lower when we impose full redistribution (i.e., subjects know that their after-tax incomes will all be the same). We attribute this still relatively high efficiency to the fact that subjects keep on trading relative well in spite of substantially lower marginal incentives. Interestingly, full redistribution increases price volatility, but this increase seems to be caused by subjects trading more aggressively in order to avoid inefficient transactions and ensure large welfare gains from redistribution. 
We endogenize the level of redistribution by having two candidates compete through tax policies on which citizens vote in simple majority elections. Consistent with median voter theories, we observe that candidates woo the poor majority with high tax rates and citizens vote in accordance to their self-interest. This behavior yields (almost) fully egalitarian income distributions in nearly all societies. The effects observed in the double auction market with full redistribution translate to those with endogenous taxation, but are slightly weaker because winning tax rates are (anticipated to be) somewhat smaller than one.

We also give citizens the opportunity to lobby by transferring money to the candidates, who are not obliged to choose a specific tax policy after being lobbied. In this way, the rich minority can use their superior financial means to try to induce candidates to reduce income redistribution. Although we observe substantial amounts of transfers in the first period, lobbying by the rich breaks down due to counteractive lobbying by the poor, miscoordination between rich citizens, and miscoordination between candidates. Consequently, candidates end up choosing high tax rates. With exception of the high lobbying transfers in the first period, these results are consistent with our equilibrium predictions. In other words, in our experiment the "one person, one vote" principle determines the final income distribution.

Our experimental results support the notion that both double auction markets and simple majority elections with compulsory voting remain as reliable in coexistence as they are in isolation. Consequently, given that we see high redistribution rates in our experiment, the worldwide persistence of poor majorities in democracies must be attributed to institutions and factors other than those studied in this paper. In this sense, the advantage of our basic setup is that it can easily accommodate additional influences. For instance, one can study the effect of giving the rich outside options (e.g., by moving to societies with lower taxes or by switching to leisurely activities), which might induce poor citizens to support lower levels of redistribution. Another option is to help candidates and lobbyists reach implicit or explicit agreements by facilitating coordination among the rich (for them to better target their transfers) or among the candidates (to react in unison to lobbying efforts). For example, Großer, Reuben, and Tymula (2009a) show experimentally that if only one rich 
subject (e.g., an organized special interest group) but no poor subjects can transfer money to the candidates and there is repeated interaction, then lobbying can indeed influence redistribution. In another study (Großer, Reuben, and Tymula 2009b), the same authors show similar results for the situation where the rich can reward candidates after elections are held. Finally, future research could limit the amount of information provided to citizens and candidates in our experiment. For example, if citizens are little or not informed about the distribution of individual and average pre-tax incomes, overconfidence may lead them to believe they earn more than average and, hence, to vote for less redistribution.

Overall, our experiment is as a first step to obtain a better understanding of the interaction of markets and elections and its welfare consequences. Naturally, in the laboratory we have to choose specific procedures and parameters. We want to stress, however, that our choices are nonetheless representative of many of the incentives people face outside of the laboratory. In this respect, we believe that our experiment provides evidence that markets that generate stark income inequalities and elections that redistribute this income can work well in unison.

\section{Appendix A - Market equilibrium and redistribution}

Here, we analyze how expected redistribution may affect the posting and accepting of prices in double auction markets. A seller $i$ 's after-tax market income from selling her $k^{\text {th }}$ unit is given by

$$
\begin{aligned}
\pi_{i k, t a x}^{S} & \equiv \pi_{i k}^{S}+t\left(\bar{\pi}_{u}-\pi_{i k}^{S}\right) \\
& =d_{i k}\left(p_{i k}-c_{i k}\right)+t \frac{u-1}{u}\left[\bar{\pi}_{u,-i k}-d_{i k}\left(p_{i k}-c_{i k}\right)\right]
\end{aligned}
$$

and a buyer $i$ 's after-tax market income from buying her $k^{\text {th }}$ unit by

$$
\begin{aligned}
\pi_{i k, t a x}^{b} & \equiv \pi_{i k}^{b}+t\left(\bar{\pi}_{u}-\pi_{i k}^{b}\right) \\
& =d_{i k}\left(v_{i k}-p_{i k}\right)+t \frac{u-1}{u}\left[\bar{\pi}_{u,-i k}-d_{i k}\left(v_{i k}-p_{i k}\right)\right]
\end{aligned}
$$

where $n$ denotes the number of traders (we assume that there is at least one seller and one buyer); $u \equiv \sum_{h=1}^{n} m_{h}$ the total number of units in the market, and $m_{i} \geq 1$ the number of units each $i$ possesses (recall that we used $n=10, m_{i}=2$ for all $i$, and hence $u=20$ in our experiment). Moreover, $\bar{\pi}_{u} \equiv \frac{1}{u} \sum_{h=1}^{n} \sum_{r=1}^{m_{i}} \pi_{h r}$ gives the average pre-tax income of all units 
and $\bar{\pi}_{u,-i k} \equiv \frac{1}{u-1}\left[\sum_{h=1}^{n} \sum_{r=1}^{m_{i}} \pi_{h r}-\pi_{i k}\right]$ the average pre-tax income of all units in the market other than the $k^{\text {th }}$ unit of $i$. Using expressions (1) and (2), we can derive a seller's minimum willingness to accept for her $k^{\text {th }}$ unit, $p_{\min , k}^{S}$, and a buyer's maximum willingness to pay for her $k^{\text {th }}$ unit, $p_{\text {max, } k}^{b}$. Specifically, seller $i$ has an incentive to sell her $k^{\text {th }}$ unit at price $p$ if her expected after-tax market income from trading this unit is at least as high as that from not trading, or formally, iff

$$
\begin{aligned}
E_{i}\left[\pi_{i k, t a x}^{s} \mid d_{i k}\left(p, c_{i k}, \kappa, \beta_{i}\right)=1\right] & \geq E_{i}\left[\pi_{i k, t a x}^{s} \mid d_{i k}\left(p, c_{i k}, \kappa, \beta_{i}\right)=0\right] \\
\Rightarrow\left(1-t \frac{u-1}{u}\right)\left(p-c_{i k}\right) & \geq t \frac{u-1}{u} \times \Delta E_{i}\left[\bar{\pi}_{u,-i k}\right]
\end{aligned}
$$

and similarly, buyer $i$ has an incentive to buy her $k^{\text {th }}$ unit at price $p$ iff

$$
\begin{aligned}
E_{i}\left[\pi_{i k, t a x}^{b} \mid d_{i k}\left(p, v_{i k}, \kappa, \beta_{i}\right)=1\right] & \geq E_{i}\left[\pi_{i k, t a x}^{b} \mid d_{i k}\left(p, v_{i k}, \kappa, \beta_{i}\right)=0\right] \\
\Rightarrow\left(1-t \frac{u-1}{u}\right)\left(v_{i k}-p\right) & \geq t \frac{u-1}{u} \times \Delta E_{i}\left[\bar{\pi}_{u,-i k}\right]
\end{aligned}
$$

where $\Delta E_{i}\left[\bar{\pi}_{u,-i k}\right] \equiv E_{i}\left[\bar{\pi}_{u,-i k} \mid d_{i k}\left(p, c_{i k}, \kappa, \beta_{i}\right)=0\right]-E_{i}\left[\bar{\pi}_{u,-i k} \mid d_{i k}\left(p, c_{i k}, \kappa, \beta_{i}\right)=1\right]$ denotes the difference in $i$ 's subjective expectations about the average pre-tax incomes at market closing of all units other than her $k^{\text {th }}$ unit for not trading, $d_{i k}()=$.0 , and trading, $d_{i k}()=$. (note that a positive $\Delta E_{i}\left[\bar{\pi}_{u,-i k}\right]$ means that $i$ expects her unit to contribute relatively less to welfare than other units that may still be traded); $\kappa$ denotes the common knowledge obtained about all market activity in the current period up till her decision to trade (e.g., about the specific trading path so far); and $\beta_{i}$ denotes her subjective beliefs about all other costs and values in the market. ${ }^{27}$ Note from conditions (3) and (4) that a trader $i$ 's expected after-tax market income from trading her $k^{\text {th }}$ unit at price $p$ consists of a private component ( $p-c_{i k}$, weighted by $1-t \frac{u-1}{u}$, on the left-hand sides) and a welfare component $\left(\Delta E_{i}\left[\bar{\pi}_{u,-i k}\right]\right.$, weighted by $\frac{u-1}{u}$, on the right-hand sides). Rearranging both conditions yields

$$
p \geq p_{\min , k}^{s} \equiv c_{i k}+\frac{t \frac{u-1}{u}}{1-t \frac{u-1}{u}} \times \max \left[0, \Delta E_{i}\left[\bar{\pi}_{u,-i k}\right]\right]
$$

and

\footnotetext{
27 Note that $\kappa$ and $\beta_{i}$ are typically not independent from each other-that is, subjective beliefs about all other costs and values in the market are updated based on observed market activity. However, for our purpose this relationship does not need to be specified further.
} 


$$
p \leq p_{\text {max }, k}^{b} \equiv v_{i k}-\frac{t \frac{u-1}{u}}{1-t \frac{u-1}{u}} \times \max \left[0, \Delta E_{i}\left[\bar{\pi}_{u,-i k}\right]\right]
$$

where the 'min' and 'max' operators account for the trading rules that $p \geq c_{i k}$ and $p \leq v_{i k}$. Condition (5) shows that seller $i$ may only have an incentive to sell her $k^{\text {th }}$ unit if the price is sufficiently higher than her costs and, similarly, condition (6) shows that buyer $i$ may only have an incentive to buy her $k^{\text {th }}$ unit if the price is sufficiently lower than her value. In other words, a seller's minimum willingness to accept may increase and a buyer's maximum willingness to pay may decrease. As a consequence, the supply and demand curves shown in Figure 1 may shift inwards, and stronger so for higher $\Delta E_{i}\left[\bar{\pi}_{u,-i k}\right]$ and higher tax rates, $t$

(because $\left.\partial\left(t \frac{u-1}{u} / 1-t \frac{u-1}{u}\right) / \partial t=(u-1) / u\left(1-t \frac{u-1}{u}\right)^{2}>0\right) .{ }^{28}$ Such inward shifts essentially mean that trading may become more aggressive-that is, sellers and buyers may post higher and lower prices, respectively. If their subjective beliefs about her own unit's cost or value relative to other costs and values in the market are monotonic-that is, are preserving the ranking of actual costs and values-and if subjective expectations about tax rates are not too diverse, inefficient transactions become less likely. Moreover, if $u$ and $t$ get large, possible supply and demand curve shifts can become very large (bounded by 100 and 0 ) for those units that sellers and buyers believe to be inefficient-that is, have a positive $\Delta E_{i}\left[\bar{\pi}_{u,-i k}\right]$. Note that if it is common knowledge that $E_{i}[t]=1$ for all $i$ and that everyone knows whether her units are efficient or inefficient, then there are many equilibria in which only efficient units are traded-at any feasible prices-but no inefficient units (because in our static equilibrium analysis a market price is unique for all transactions, Proposition 1 holds also for this case).

\section{Appendix B - Zero-intelligence market traders}

The simulation for zero-intelligence traders was done for the market described in subsection 2.1 and with the same number of buyers and sellers and the same costs and values depicted in Figure 1. The results presented in Table 2 are the result of running 50,000 periods. Each

\footnotetext{
${ }^{28}$ Note that since $\Delta E_{i}\left[\bar{\pi}_{u,-i k}\right]$ is a subjective expectation, which may or may not be accurate with respect to actual average pre-tax incomes at market closing, the order of specific units may be different than shown in Figure 1.
} 
period of the simulated market followed the following sequence (the code of the simulation is available in the online appendix):

1. One citizen (a robot buyer or seller) is randomly drawn from the society, each with equal probability.

2. If the chosen citizen is a robot seller, it makes an offer by drawing a random number between the cost of its current unit and the highest possible value (using a uniform distribution). If the chosen citizen is a robot buyer, it makes a bid by drawing a random number between the value of its current unit and the lowest possible cost (using a uniform distribution). These bounds for the draws are chosen because prices below the lowest cost and above the highest value are never accepted.

3. If the chosen citizen is a robot buyer and its bid is higher than the current posted offer then the transaction occurs at the posted offer's price between the robot buyer and the corresponding robot seller. If its bid is lower than the current poster offer but higher than the current posted bid then its bid becomes the new posted bid. Lastly, if its bid is lower than the current posted bid nothing happens. If the chosen citizen is a robot seller and its offer is lower than the current posted bid then the transaction occurs at the posted bid's price between the robot seller and the corresponding robot buyer. If its offer is higher than the current poster bid but lower than the current posted offer then its offer becomes the new posted offer. Lastly, if its offer is higher than the current posted offer nothing happens.

4. Steps 1 through 3 are repeated until there are no more possible transactions or up to a maximum number of postings $x$. This maximum number of postings is determined at the beginning of each period by randomly drawing a value from the distribution $X$, where $X$ is the observed distribution of postings per period in the Market- 0 treatment. The reason we use this limit to the number of transactions is that robot traders are not restricted by the two minutes during which the market is open. In order to make the simulation as comparable to the experiment as possible, we use the number of executed transactions in Market-0 as representing the effect of the time during which the market is open. The results do not vary considerably if we 
change this assumption. Essentially, a smaller or larger mean for $X$ affects the mean number of transactions but not the other statistics.

\section{References}

Ainsworth, Scott. 1993. "Regulation lobbyists and interest group influence." Journal of Politics 55: 41-56.

Alesina, Alberto, and Dani Rodrik. 1994. "Distributive politics and economic growth." Quarterly Journal of Economics 109 (May): 465-90.

Alesina, Alberto, and Eliana La Ferrara. 2005. "Preferences for redistribution in the land of opportunities." Journal of Public Economics 89: 897-931.

Austen-Smith, David, and John R. Wright. 1992. "Competitive lobbying for a legislator's vote." Social Choice and Welfare 9: 229-57.

Austen-Smith, David, and John R. Wright. 1994. "Counteractive lobbying." American Journal of Political Science 38 (February): 25-44.

Bénabou, Roland J.M. 2000. "Unequal societies: Income distribution and the social contract." American Economic Review 90 (March): 96-129.

Bénabou, Roland J.M., and Jean Tirole. 2006. "Belief in a just world and redistributive politics." Quarterly Journal of Economics 90 (May): 699-746.

Benhabib, Jess, and Aldo Rustichini. 1996. "Social conflict and growth." Journal of Economic Growth 1: 125-42.

Benhabib, Jess, and Adam Przeworski. 2006. "The political economy of redistribution under democracy." Economic Theory 29: 271-90.

Bernheim, B. Douglas, and Michael D. Whinston. 1986. "Menu auctions, resource allocation, and economic influence." Quarterly Journal of Economics 101 (February): 1-32.

Bolton, Gary, and Axel Ockenfels. 2000. "A theory of equity, reciprocity, and competition." American Economic Review 100: 166-93.

Bosman, R., and van Winden, F. 2002. "Emotional hazard in a power-to-take game experiment." Economic Journal 112: 147-69. 
Browning, Edgar K. 2002. “The case against income redistribution.” Public Finance Review 30: $509-30$.

Camerer, Colin F. 2003. Behavioral Game Theory. Princeton University Press, Princeton.

Camerer, Colin F. and Robin M. Hogarth. 1999. "The effects of financial incentives in experiments: A review and capital-labor-production framework." Journal of Risk and Uncertainty 19: 7-42.

Davis, Douglas D., and Charles A. Holt. 1993. Experimental economics. Princeton University Press, Princeton.

Dixit, Avinash, Gene M. Grossman, and Elhanan Helpman. 1997. "Common agency and coordination: general theory and application to government policy making." Journal of Political Economy 105 (4): 752-769.

Dufwenberg, Martin, and Georg Kirchsteiger. 2004. "A theory of sequential reciprocity." Games and Economic Behavior 47: 268-98.

Esarey, Justin, Timothy C. Salmon, and Charles Barrilleaux. 2009. "What motivates political preferences? Self-interest, ideology, and fairness in a laboratory democracy." Working Paper

Falk, Armin, and Urs Fischbacher. 2006. "A theory of reciprocity." Games and Economic Behavior 54: 293-315.

Fehr, Ernst, and Klaus Schmidt. 1999. "A theory of fairness, competition and cooperation." Quarterly Journal of Economics 114: 817-68.

Fischbacher, Urs. 2007. "Z-tree: Zurich toolbox for ready-made economic experiments." Experimental Economics 10: 171-78.

Glaeser, Edward, Jose Scheinkman, and Andrei Shleifer. 2003. "The injustice of inequality." Journal of Monetary Economics 50: 199-222.

Gode, Dhananjay K., Shyam Sunder. 1993. "Allocative efficiency of markets with zerointelligence traders: Markets as a partial substitute for individual rationality." Journal of Political Economy 101: 119-37.

Goeree, Jacob K., and Charles A. Holt. 2001. "Ten little treasures of game theory and ten intuitive contradictions." American Economic Review 5: 1402-22. 
Greiner, Ben. 2004. "The online recruitment system ORSEE 2.0 - A guide for the organization of experiments in economics." University of Cologne. Working paper.

Großer, Jens, and Thorsten Giertz. 2006. “Candidates, Voters, and Endogenous Group Formation: An Experimental Study." Working Paper.

Großer, Jens, and Arthur Schram. 2009. "Public opinion polls and voter turnout: An experimental study." Working paper.

Großer, Jens, Ernesto Reuben, and Agnieszka Tymula. 2009a. "Buying low tax rates: An experimental study of lobbying and redistributive policies". Working paper.

Großer, Jens, Ernesto Reuben, and Agnieszka Tymula. 2009b. “Avoiding redistribution by rewarding politicians: An experimental study." Working paper.

Grossman, Gene M., and Elhanan Helpman. 2001. Special interest politics. MIT Press: Cambridge, Massachusetts.

Isaac, R. Mark, and James M. Walker. 1988. “Communication and free-riding behavior: The voluntary contribution mechanism." Economic Inquiry 26: 585-608.

Kagel, John H., and Alvin E. Roth. 1995. Handbook of experimental economics. Princeton University Press: Princeton.

Levine, David K. 1998. "Modeling altruism and spitefulness in experiments." Review of Economic Dynamics 1(3): 593-622.

Levine, David K., and Thomas R. Palfrey. 2007. "The paradox of voter participation? A laboratory study." American Political Science Review 101 (1): 143-58.

McKelvey, Richard D. and Peter C. Ordeshook. 1990. “A decade of experimental research on spatial models of elections and committees." In M.J. Hinich and J. Enelow (eds.): Government, Democracy, and Social Choice. Cambridge University Press: Cambridge.

McKelvey, Richard D., and Thomas R. Palfrey. 1995. "Quantal response equilibrium for normal form games." Games and Economic Behavior 10: 6-38.

McKelvey, Richard D., and Thomas R. Palfrey. 1998. "Quantal response equilibrium for extensive for games." Experimental Economics 1: 9-41.

Meltzer, Allan H., and Scott F. Richard. 1981. "A rational theory of the size of government." Journal of Political Economy 89: 914-27. 
Milanovic, Branko, Peter H. Lindert, and Jeffrey G. Williamson. 2007. "Measuring Ancient Inequality." NBER Working Paper \#13550.

Persson, Torsten, and Guido Tabellini. 2000. Political economics: Explaining economic policy. MIT Press: Cambridge, Massachusetts.

Potters, Jan, and Frans van Winden. 1992. "Lobbying and asymmetric information." Public Choice 74: 269-92.

Potters, Jan, and Frans van Winden. 2000. "Professionals and students in a lobbying experiment: Professional rules of conduct and subject surrogacy." Journal of Economic Behavior and Organization 43: 499-522.

Romer, Thomas. 1975. "Individual welfare, majority voting and the properties of a linear income tax." Journal of Public Economics 7: 163-85.

Rosen, Harvey S., and Ted Gayer. 2007. Public Finance. McGraw-Hill: Boston.

Ruffle, Bradley J. 2005. "Tax and subsidy incidence equivalence theories: Experimental evidence from competitive markets." Journal of Public Economics 89: 1519-42.

Smith, Vernon L. 1962. "An experimental study of competitive market behavior.” Journal of Political Economy 70: 111-37.

Tullock, Gordon. 2005. The rent seeking society: The selected works of Gordon Tullock, Vol. 5. C.K. Rowley (ed.). Liberty Fund, Inc.

Tyran, Jean-Robert, and Rupert Sausgruber. 2006. "A little fairness may induce a lot of redistribution in democracy." European Economic Review 50: 469-85.

van Winden, F. 2001. "Emotional hazard exemplified by taxation-induced anger." KYKLOS 54: 491-506.

White, Halbert. 1980. "A heteroskedasticity-consistent covariance matrix estimator and a direct test of heteroskedasticity." Econometrica 48(4): 817-38.

World Bank, Annual Report 2007. Washington DC 